\title{
Nursing And Midwifery Students' Lived Experiences Of Faculty Caring And Uncaring Behaviours On Their Learning: A Phenomenology Study
}

\author{
Mep Chipeta (MSc, RN/RM) \\ Alice Konyani Msiska (MSc, RN/RM) \\ Gertrude Munthali Moyo (MSc, RN/RM) \\ Ellemes Phuma Ngaiyaye (PhD, RN/RM) \\ Atupele Malema Zimba (MSc, RN/RM) \\ Mzuzu University, Nursing and Midwifery Department,Luwinga, Malawi \\ Belinda Gombachika (Associate Professor, RN/RM) \\ Kamuzu College of Nursing, Blantyre, Malawi \\ Balwani Chingatichifwe Mbakaya (PhD, MPH) \\ St Johns Institute for Health, Mzuzu Malawi
}

Doi:10.19044/esj.2021.v17n3p205

Submitted: 04 November 2020

Accepted: 25 December 2020

Published: 31 January 2021
Copyright 2021 Author(s)

Under Creative Commons BY-NC-ND

4.0 OPEN ACCESS

Cite As:

Chipeta M., Gombachika B., Mbakaya B.C., Konyani M. A., Munthali G., Phuma-Ngaiyaye E. \& Malema A.Z., (2021). Nursing and Midwifery students' lived experiences of faculty caring and uncaring behaviours on their learning: A phenomenology study. European Scientific Journal, ESJ, 17(3), 205.

https://doi.org/10.19044/esj.2021.v17n3p205

\begin{abstract}
Background: A caring environment in nursing education is one of the most essential factors for empowering students, which is achieved through trust and open academic communication. Aim: To explore the experiences of faculty caring and uncaring behaviours on students learning from the perspective of university nursing and midwifery students. Methods: Descriptive phenomenology was used to collect data from 10 nursing and midwifery students who were purposively selected at a baccalaureate nursing and midwifery school at a public university in Malawi. Data were collected through semi-structured interviews from August 24 ${ }^{\text {th }}$, 2015 to September $30^{\text {th }}$, 2015 and analysed using Colaizzi's (1978) method. Ethical considerations were followed.
\end{abstract}


Results: Two sub-themes which emerged under the main theme of experiences of faculty caring behaviours which were: (1) Increased motivation (2) Increased confidence and Competence, whilst three sub-themes which emerged under the main theme of experiences of faculty uncaring behaviours were: (1) Poor performance (2) A risk to patients (3) Feeling helpless and embarrassed. Conclusion: Experiences of students with caring and uncaring faculty had an influence on students learning, personal well-being and on their ability to effectively care for their patients. The study recommends that faculty members should critically analyse their actions and embrace those caring behaviours that facilitate the process of creating a conducive learning environment. In addition, there is need to develop a clear policy stipulating the role of student personal advisors and how students can engage them.

Keywords: Faculty, Caring, Uncaring, Experiences, Nursing Education, Nursing Students

\section{Introduction and Background}

Faculty-student caring relationship in nursing education enhances students' learning experiences to care, desire to care for others and selfactualization (Salehian et al., 2017). One of the most identifiable determinants of academic outcomes of undergraduate nursing students in the current literature is student-faculty relationships (Ingraham et al., 2018). According to Hawks (1992), a caring environment in nursing education is one of the most essential factors for empowering students, which is achieved through trust and open academic communication (cited in Begum \& Slavin, 2012). Therefore, nurse educators are encouraged to critically analyse their role in teaching nursing students and to consider whether their actions create barriers to or facilitate the process of relationship formation for student nurses (Jamshidi et al., 2016).

Over the last two decades there has been a movement in nursing education from a behaviorist base toward a process grounded in humanism (Gillespie, 2002). The philosophy of the humanistic paradigm is embodied in the constructs of caring, learning, participation and reflection (Paterson \& Crawford, 2004). Review of the nursing and education literature reveals a paucity of research examining the conceptualized student-teacher relationship proposed within the humanistic paradigm. Furthermore, connection as part of the relationship has been reported in research literature exploring caring student-teacher interactions (Gillespie, 2002). It is through this interaction that the two show caring relationship where one cares and the other one receive the care. It sees the teacher in a relationship with students which acts as a complete circle of a caring interaction. 
Faculty need to exhibit caring behaviours to their students in order to create an environment that is conducive for learning as well as instilling behaviours that will continue for the rest of their nurse's life (Beck, 2001) and develop the competence of caring (Labrague et al., 2015). Noddings (2005) argued that educators must provide a climate that enables students to internalize caring behaviours through the interactions that are experienced between the teacher as the one caring and the students as the recipient of caring.

The experiences of student with a caring faculty have been reported in literature. In 2015, Labrague et al. conducted a study on the impact of instructors caring on student's perceptions and their own caring behaviours. It was concluded that instructors caring behaviours influenced nursing students caring behaviours positively. Through positive faculty modelling and role modelling, nursing students can be professionally trained to develop the competence of caring. In her study on the impact of faculty caring on student retention and success at Kent State University in Ohio, United States, McEnroe - Petitte (2011) found that faculty caring impact positively on student's retention and success. She concluded that development of a caring curriculum that provides a holistic approach, which calls for students to learn about care and caring is needed. Literature also supports that if nursing students are cared for, they also learn the ability to care for their patients and have a sense of growth and change (Begum \& Slavin, 2012; Nodding, 2005). In addition, Brown (2011) asserted that a caring curriculum can purposefully integrate structures that support students' awareness of the self as caring beings while synthesizing a holistic approach to nursing practice.

Despite the valuable results demonstrated by earlier studies in this regard, only some parts of caring knowledge have been processed in education (Salehian et al., 2017); making it inadequate to draw a comprehensive picture of the impact of faculty caring concept in nursing education. In addition, the fact that the studies yielded different results on the impact of caring and uncaring faculty behaviours justifies the need to explore the situation in Malawian contexts.

\section{Study Design}

The study employed qualitative approach, utilizing descriptive phenomenology based on Husserl's philosophical ideas as a philosophy and research method. Husserl's philosophical ideas are based on the assumption that experience as perceived by human consciousness has value and should be employed in research as a means of describing and interpreting human experiences of learning (Husserl, 1970). The phenomenology method was chosen to describe nursing midwifery students lived experiences of faculty's caring and uncaring behaviours on their learning. It is about the world as 
experienced in a particular phenomenon that is at the core of that experiencing (Creely, 2016). It is believed that only those who live the experience can describe it (Mapp, 2013). Caring is a human experience and this justified the need for a phenomenological inquiry

Husserlian phenomenologists believe that the process of learning and constructing the essence of an experience is through intensive dialogue with persons who are living the experience; this is the reality of that experience (Mapp, 2013; Neubauer et al., 2019) In Phenomenological research, the researcher starts with choosing a phenomenon of interest which in this study was "faculty caring". Interest in "faculty caring" developed as a result of professional experience in working with students. Although it was obvious that faculty were active participants in students' welfare, limited research had been carried out on how their caring or uncaring behaviors may influence student learning.

\section{Study Setting and Sample}

The study was conducted at a Public University located in the northern part of Malawi. A purposeful sampling technique was used to recruit 10 study participants subject to the theory of data saturation. The sample comprised of 6 females and 4 male nursing midwifery students from a total population of 66 students. The sample was drawn from third and fourth year students because they were regarded to have had adequate experience with faculty and could ably provide rich data.

\section{Data Collection Instrument and Approach}

Each participant was regarded as an expert and the process of data collection was an intersubjective interaction which resulted into mutual construction of the meaning (Reuther, 2014). Data were collected through dialogue using a semi-structured interview guide which allowed the participants to express themselves fully regarding their experience. Ten (10) face to face dialogue sessions were conducted with each dialogue lasting about 45 minutes on average. Data collection took place from August $24^{\text {th }}, 2015$ to September $30^{\text {th }}$, 2015. The first author facilitated the dialogue sessions with all data tape recorded and transcribed verbatim for each participant. Collection of data was conducted in a quiet room within the university premise. Field notes were used to verify issues that arose during data collection and the interview environment. The researcher had an exclusive dialogue with the participants who had shared experiences of faculty caring and uncaring behaviours on their learning as it had been lived. Probes included: probe for examples of the effects or impact of a caring or uncaring behaviour; feelings during that incidence; feelings now and how the participants would have loved 
to be treated. Also probed for thoughts, feelings and perceptions about the experience.

One of the concepts of Husserl's philosophy is transcendental subjectivity which means that the influence of the researcher on the inquiry is continuously assessed and biases and preconceptions neutralized, so that they do not affect the object of study (Creely, 2016). To achieve this, the researcher employed the concepts of bracketing, intuition and reflexivity throughout the study. Considering the relationship between the researcher and the participants (i.e. lecturer and students), the researcher adopted a self-critical stance to the study, the participants, their role, relationships and assumptions in order for the study to be more credible and dependable (Holloway \& Wheeler, 2010) In the study, methodological rigor was achieved in the following way: Firstly, in order to ensure credibility, a member checking was done whereby the researcher returned to the participants to validate the findings. Secondly, dependability was achieved by maintaining consistency in the process of data collection specifically by using the same main questions in the interview guide to all participants in order to maintain consistency of the data findings. Thirdly, conformability was achieved by incorporating participant's expressive language, presented as direct quotes from the transcribed data to provide evidence of the research findings in the report. Finally, the researcher had provided a dense description of the research methodology and the research context so as to enable someone interested in making a transfer of data findings to reach a conclusion about whether transfer can be possible or not.

\section{Data Analysis}

Data analysis was done manually and progressed following a step by step approach as guided by Colaizzi's process for phenomenological data analysis (Shosha, 2010). The first step was to transcribe verbatim the interviews that were done. All researchers were involved in the transcription to familiarise themselves with the data. The next step was to listen to the interview. The research team verified the transcription by re-reading the transcribed data while listening to the recorded data, in order to obtain a general sense about the whole context. It was important at this stage for the researcher to remain open and to stay as true as possible to the data generated in order to understand caring from the perspective of nursing and midwifery students.This step was followed by identifying significant statements that pertained to the phenomena under study whilst noting the number of participant, page number and line number. The other step was to formulate meanings from these significant statements through crystallization and condensation of what the participants had said but still using as much as possible the literal words of the participants. Then the significant statements were sorted into themes, subthemes and subcategories. This process required 
a creative insight as advocated for Colaizzi's (1978) strategy. The findings were then integrated into an exhaustive description of the phenomena, caring. Later, the fundamental structure of the phenomena, caring was described. Finally, validation of findings was done by returning to the participants to compare the researchers' descriptive results with their experience.

\section{Ethical Consideration}

Ethical approval to conduct the study was obtained from a University's Research and Ethics Committee with reference number P.04/15/1714. Permission was sought from the University administration. Participants provided a written informed consent to take part in the study. The researcher respected the participants' rights in reference to: privacy, confidentiality and anonymity to their identity, self-determination and fair treatment

\section{Results}

The study findings depict Malawian students' experiences of faculty caring behaviours on their learning. The following themes emerged from the study: experiences of faculty's caring behaviours to students learning, and experiences of faculty's uncaring behaviours to students learning.

\section{Experiences of Faculty's Caring Behaviours to Students Learning}

The following subthemes emerged as experiences of faculty caring behaviours to students: increased motivation, increased confidence and competence

\section{Increased motivation.}

When lecturers made themselves available to talk about students' personal problems, students felt relieved from the stress that affected them and were motivated to study more. They were able to concentrate in their studies because they felt that the caring encounter they had with faculty provided a solution to some personal issues that affected them academically. This is reflected in the following statement from some of the participants:

"When this particular lecturer made himself available to talk, I felt relieved and then I was happy, the issue wasn't there anymore, I was able to attend classes and everything went on well, I was able to concentrate. (01-F-4)."

While another student presented the caring experience in this manner:

"Since I was counselled, I would say that my academic work improved because I had a situation which was pulling me back, but because of the counselling, and that the faculty was really there for me when I really needed them, that made me to push myself forward in my studies." (02-F-4). 
There were also increased levels of motivation in asking lecturers for help when the students were not shouted at in the clinical setting. The participants felt the need to utilize every opportunity to learn when the lecturers are available and they were not afraid because they knew that the faculty member would assist them effectively. One participant said:

"...but the way she handled the situation and explained to ....It was just good. It also motivated me to be free to ask lecturers for help whenever they visit for clinical teaching....” (07-F-3).

\section{Increased confidence and competence.}

The participants expressed that in cases where the lecturer demonstrated a skill in the clinical area, the participants felt confident and had increased levels of competence. This had a positive experience on their patients' care as they were able to provide quality nursing care and were confident enough to teach fellow students. One participant said:

"From the day I was demonstrated to on how to take vital signs, I got it right and I cannot ask anybody on how to do it..... And since our midwifery lecturer demonstrated on how to assess a woman in labour, I have found it easy to note a uterine contraction from where it begins and ends. Similarly listening to a fatal heart rate...am even able to teach others..."(04-F-4).

Another participant shared the experience in this way:

"I was so satisfied with the kind of care that he gave me, the kind of knowledge he provided me with and I was able to internalise it, I don't need to read about it anymore because whatever it is that he said really made sense to me ...."(08-M-3).

The availability of the lecturers to talk to the students made other participants to do the same to colleagues who would be facing similar problems. Such experiences helped the participants to develop skills to counsel and support fellow students facing similar situations. In addition, the caring moments experienced increased the students' competence to care for patients. One of the participants expressed the following sentiments:

"On the caring part, it had a good impact as I felt I can also help fellow students facing similar problems. In addition....I felt like it improved my competence in caring for patients....and even the relationship with that supervisor, it is good. If I encounter a problem, it's easy for me to go and ask for help.” (06-F-3).

\section{Experiences of Uncaring Faculty Behaviours to Students Learning}

Uncaring faculty behaviours had negative influences on students learning and professional career. The following subthemes emerged: poor performance, a risk to patients and feeling helpless and embarrassed. 


\section{Poor performance}

It was noted that lack of supervision and demonstrations of clinical skills was viewed as uncaring to students and this had a negative influence on students' performance. It increased fears on their performance as students and also when they qualify. Most participants felt it affected their performance when what was not demonstrated appeared during Objective Structured Clinical Examination (OSCE). The participants failed terribly because the skills were not demonstrated to them and this affected their grades. One participant made the following comment:

"In second year, we learnt something to do with oxygen therapy, but on how to administer that oxygen therapy, we were not demonstrated and then, during an OSCE, that procedure came in an exam and seriously we failed miserably. And in midwifery, we were asked to demonstrate procedures that we were not demonstrated to us and we didn't know what to do." (04-F-4)

Another participant said:

"And also another thing is that we finished our high risk midwifery classes without being demonstrated some of the procedures. And then when we went to the clinic, the procedures were scarce, we could not come across any.... and then one of the procedures had to appear in our OSCE of which maybe eighty percent of the class did not do well ... So that was uncaring on my part”. (03-F-4).

In addition to poor performance whilst in college, some participants felt that they were not adequately prepared to practice when they qualified and this increased their fears on how they will practice after qualification. This was expressed as follows:

"Apart from the fact that members from other schools would be laughing at us, that we are not capable, it also creates fears on how I will perform when I graduate, especially when I encounter such situations." (05-M-4).

\section{A risk to patients.}

As a result of lack of demonstrations of clinical skills before clinical placement, participants felt inadequately prepared to handle patients thereby posing a risk to patients' lives. They lacked confidence to handle patients on their own or with minimal supervision. This was evident when they encountered some cases and were alone in the ward. One participant in fear expressed this:

"Lack of supervision and demonstration discouraged me and gave me a feeling that am not competent in doing procedures because whenever I encountered those procedures I panicked... I remember I encountered a breech delivery, seriously it was tough and that baby 
would have been dead by now... because of lack of skill and I had no idea on how to deliver a breech, I twisted everything." (04-F-4).

\section{Feeling helpless and embarrassed.}

The finding also revealed that when lecturers shout at students in the presence of patients, it made them feel helpless, incompetent and ashamed and not wanting to continue caring for the same patients and sometimes made themselves busy for nothing when the lecturers came for supervision. One of the participants gave the following account:

"The way he spoke to me, I felt like I looked stupid in front of the patients whom I spend much of my days with, working and doing things to them. I felt patients would lose trust in me to say I don't know what am doing, they wouldn't feel safe... it really reduced my self-esteem working in that ward." (08-M-3).

As a result of being shouted at or embarrassed in the presence of patients, some participants would run away from faculty members when they came for supervision or clinical teaching. This was because some lecturers focused on fault finding instead of teaching. this made students to absentee themselves and sometimes run away or made themselves busy to avoid attracting attention from the faculty member. This is what one participant said:

"Some lecturers when they have come for clinical teaching they don't teach you, they observe mistakes and then from those mistakes they will shout at you. So when I see some lecturers I run...I just say let me take some blood samples and go to the laboratory, and then go for lunch without meeting them.” (10-M-3).

\section{Discussion and Recommendations}

The study revealed that faculty's availability for clinical teaching was viewed as caring and had a positive learning experience to students. Labrague et al. (2015) showed that faculty's availability and provision of a supportive learning environment were important components to caring interaction. This interaction relates to what Gillespie (2002) described as being connected or non-connected. Through this interaction, the students were guided, appraised, supported, advised and counselled on different issues regarding their personal and academic needs. As a result, the students were motivated and their learning improved (Begum \& Slavin, 2012).

However, the majority of the students indicated that some faculty were un-approachable and not available to assist with personal needs depicting a non-connected relationship between faculty and students according to Gillespie (2002). Unavailability has been recorded in literature as instructors' uncaring behaviours (Zamanzadeh et al., 2015). Both personal and academic interactions reflect lack of connection in meeting professional and personal 
caring needs of students (Gillespie). The need of students to have faculty available for them is consistent with Garza (2009) who also stated that inability to approach lecturers' affects students learning.

Students perceived a caring interaction as one in which support is provided by the teacher. Froneman et al., (2016) reveal that supportive environment where learning can take place not only improve the relationship between learners and staff, but also has a positive effect on the students' academic outcomes. The students' desire to have faculty available to them could be as a result of the clinical environment in Malawi, which is faced by a number of challenges like shortage of nursing staff as well as lack of equipment which negatively impact students' learning. (Msiska, Smith, \& Fawcett, 2014). It could therefore be argued that lack of supportive supervision by faculty members would be equated to students being seen as 'lost sheep' and this reflects lack of relationship between the students and faculty. Students are left in an environment where learning is very unlikely especially when clinical nurses focus on meeting patients' needs and not student's needs (Bvumbwe, Malema, \& Chipeta, 2015).

Lack of clinical supervision negatively influenced students learning as it did not just deprive them of the much needed knowledge and skills but they were also a risk to patients due their incompetence and unskilful acts. The findings reflect a situation consistent to what (Msiska, Smith, \& Fawcett (2014) found that leaving unsupervised students put patients' well-being at risk and raises the issue of patient safety within learning and caring encounters. On the other hand, the availability of faculty members in the clinical area to teach students was perceived as a caring behaviour. When students were taught in the clinical area, they felt good, empowered and motivated to learn more, developed confidence to care for patients but also to teach others. The results of perceived climate of caring and its influence to students are consistent with previous researches (Beck, 2001; Begum and Slavin, 2012; Hall, 2010; Labrague et al., 2015; Zamanzadeh et al., 2015; Henderson et al., 2019). Zamanzadeh et al., (2015) found that students developed confidence through caring which was ranked as the second most important caring attribute. When students perceived caring in their faculties, who showed a personal level of care and helped students build their confidence, students were better apt to listen and learn (Henderson et al., 2019). The meta-synthesis study by Beck (2001) found that caring by being available promotes both personal and professional growth which translates into satisfied students.

Noddings (2005) recorded that a sense of being cared for is vital to the individual's ability to care for others. Additionally, Murphy et al. (2009) asserted that support for nursing students during their academic experiences is important to equip them with the abilities to care. Labrague et al. (2015) also asserted that if the nurse educator is being perceived as a caring individual, 
those around them will be able to pick up similar perceptions and carry on caring actions worthy of a nurse. It was worth noting that caring not only affected the students when at school, but it had a life-long bearing on them as persons but also as professional beings. Begum and Slavin (2012) argued that caring for students and nurturing a caring attitude in nursing education is significant and important as this is the first place for students to learn about the most significant values and essence of their profession.

The study also revealed that the students' experience with an uncaring faculty, taught them a lesson that they would not want to treat another person the way they were treated. Ma et al. (2014) found that both caring and uncaring experiences can promote learning about caring in a way of reflective practice. Implying that the uncaring experiences taught them what caring really entails. Thus, caring by being available in nursing education is not only a source of empowerment and development but also results in enhanced confidence, motivation, personal satisfaction, inspiration, and in developing of a caring attitude in both students personal and professional lives (Begum \& Slavin, 2012). Therefore, faculty members should be available to support students learning in the clinical area.

Shouting at students in the presence of patients, had a negative learning experience on students in the clinical area as it made the students feel helpless and embarrassed. Khamedi et al. (2010) argued that the need to be respected is one of the basic needs of humans in Maslow's hierarchy of needs pyramid; it can facilitate students' achievement of educational goals. Consistent with the current study, the students felt that in situations where students are doing something that is not life threatening, they would prefer a lecturer to intervene in a calm manner. It showed that the students felt un-respected when faculty members shouted at them in the presence of patients in the clinical setting. The students resorted to running away when such faculty members came for clinical supervision. Contrary to the findings in this study, Lasiter et al. (2012) found that perceived incivility and intimidation in the clinical setting caused students to make errors in clinical judgment. These findings illustrate the importance of the educators' calm disposition and effective communication skills (Msiska, Munkhondya \& Chilemba, 2014).

\section{Conclusion}

Absence of faculty to support students denotes negative learning experience on the students as it did not just deprive them of the much needed knowledge and skills but they were also a risk to patients due to their incompetence and unskilful acts. Students perceived the availability of faculty members to teach them in the clinical area as a caring behaviour which posed as a positive learning experience during study and to their professional carrier as well. In countries where clinical teaching and learning is a challenge due to 
inadequate lecturers, it is important to use competent fulltime clinical preceptors so that students are supported. In addition, there is need for faculty members to learn to approach students in a calm and respectful manner. Such being the case, there is need for faculty members to undergo orientation programs on teaching and learning for them to learn and improve on their behaviours so that they are perceived as caring. In addition, there is need to evaluate students' performance and put in place feedback mechanisms to hear the voices of students so that a caring atmosphere is created in nursing education.

\section{Limitation of the Study}

This study used purposive sampling to enrol participants on the criterion of level of experience (level 3 and level 4 students) and ability to articulate their experience. As such, it may not guarantee that all voices were sufficiently heard. The study was also carried out at a single nursing college from the many nursing colleges in Malawi thereby limiting the transferability of the findings.

\section{Funding Statement}

No funding

\section{Declaration of Conflicting Interests}

The authors declare that they have no conflict of interest.

\section{Appendix I : Interview Guide}

Participants code

Date

\section{Demographic data}

1. Gender

2. Age of student

3. Level of study

\section{Questions and Probes}

1. Would you describe any experience or situation you have with faculty you would term a caring interaction? (Thoughts, feelings and perceptions about the experience).

2. What experiences did you have as a student following that caring encounter. (both positive and negative experiences on your learning? Probe for examples of the effects or impact of that caring behaviour; feelings during that incidence; feelings now. 
3. Would you describe any experience or situation you have with faculty you would term an uncaring interaction? (Thoughts, feelings and perceptions about the experience).

4. What experiences did you have as a student following that uncaring encounter. (both positive and negative experiences on your learning? Probe for examples of the effects/ impacts of that uncaring behaviour; feelings during that experience; feelings now; how you would have loved to be treated.

\section{References:}

1. Beck, C. T. (2001). Caring within nursing education: A metasynthesis. Journal of Nursing Education, 40(3), 101 - 109.

2. Begum, S., \& Slavin, H. (2012). Perceptions of "caring” in nursing education by Pakistan nursing students: An exploratory study. Nursing Education Today, 32(3), 332 - 336.

3. Brown, L. P. (2011). Revising our roots: Caring in nursing curriculum design. Journal of Nursing Education in Practice, 11(6), 360 - 364. DOI:10.1016/j.nepr.2011.03.007

4. Bvumbwe, T., Malema, A., \& Chipeta, M. (2015). Registered nurses' experiences with clinical teaching environment in Malawi. Open Journal of Nursing, 5, 927 - 934. http://dx.doi.org/10.4236/ojn

5. Coyle - Rogers, P. (2004). Shared success: The challenge of caring for today's health occupation educators. Journal of Career and Technical Education, 20(2), 9.Garza, R. (2009). Latino and White high school students' perception of caring behaviours: Are we culturally responsive to our students. Urban Education, 44, 297.

6. Creely,. (2016). 'Understanding things from within'. A Husserlian phenomenological approach to doing educational research and inquiring about learning. International Journal of Research \& Method in Education. 41. 10.1080/1743727X.2016.1182482

7. Froneman, K., Du Plessis, E., \& Koen, M. P. (2016). Effective educator-student relationships in nursing education to strengthen nursing students' resilience. Curationis, 39(1), 1595. https://doi.org/10.4102/curationis.v39i1.1595

8. Gillespie, M. (2002). Student-teacher connection in clinical education. Journal of Advanced Nursing, 37(6), 566 - 576.

9. Hall, L. (2010). Perceptions of faculty caring: Comparison of distance and traditional graduate nursing students. Indiana State, Terre Haute, Indiana.

10. Henderson, A., Fox, R. \& Malko-Nyhan, K. (2006). An evaluation of preceptors' perceptions of educational preparation and organizational support for their role. J Cont Educ Nurs, 37 (3), 130 -136 
11. Henderson, D., Sewell, K. A., \& Wei, H. (2019). The impacts of faculty caring on nursing students' intent to graduate: A systematic literature review. International Journal of Nursing Sciences, 7(1), 105111

12. Holloway, I., \& Wheeler, S. (2010). Qualitative research in nursing and healthcare (3rd ed.). United Kingdom: Wiley-Blackwell.

13. Husserl, E. (1970). The Crisis of European Science and Transcendental

14. Phenomenology. An Introduction to Phenomenological Philosophy, edited and transl. D. Carr. Evanston: Northwestern University Press.

15. Jamshidi, N., Molazem, Z., Sharif, F., Torabizadeh, C., \& Kalyani M.N. (2016). The Challenges of Nursing Students in the Clinical Learning Environment: A Qualitative Study. The Scientific World Journal.

16. Ingraham, I. C., Davidson, S. J., \& Yonge, O. (2018). Student-faculty relationships and its impact on academic outcomes. Nurse Education Today, 71:17-21. doi: 10.1016/j.nedt.2018.08.021.

17. Khamedi, Z., Imani, E., Naghizadeh, F., Askarnia, M., \& Hajizadeh, N. (2010). Nursing students viewpoint about characteristics of ideal clinical instructor. Journal of Urmia Nursing and Midwifery Faculty, $8(2), 61-8$.

18. Labrague, L. J., McEnroe - Petitte, D. M., Papathanasiou, I. V., Edet, O. B., \& Amlappan, J. (2015). Impact of instructors' caring on students perceptions of their own behaviour. Journal of Nursing Scholarship, 47(4), 338 - 46. DOI: 10.1111/jnu.12139.

19. Lasiter, S., Marchiondo, L., \& Marchiondo, K. (2012). Student narratives of faculty incivility. Nursing Outlook, 60(3), $121-126$.

20. Letzkus, M. W. (2005). Nursing students' perceptions of a caring clinical instructor. Graduate School of Education and Psychology, Pepperdine University, Malibu, CA

21. Levett-Jones, T., Lathlean, J., Higgins, I., \& McMillan, M. (2009). Staff-student relationships and their impact on nursing students' belongingness and learning. Journal of Advanced Nursing, 65(2), 316324.

22. Ma, F., Li, J., Liang, H., Bai, Y., \& Song, J. (2014). Baccalaureate nursing student's perspective on learning about caring in China: A qualitative descriptive study. BMC Medical Education, 14(42).

23. Mapp T. (2013) Understanding phenomenology: The lived experience. British Journal of Midwifery., 16:5.https://doi.org/10.12968/

24. McEnroe - Petitte, D. (2011). Impact of faculty caring on student's retention and success. Teach. Learn. Nurs, 6(2), $80-83$. 
25. McGregor, A. (2007). Academic success, clinical failure: Struggling practices of a failing student. Journal of Nursing Education, 46, $504-$ 511.

26. Msiska, G., Smith, P., \& Fawcett, T. (2014). The "lifeworld" of Malawian undergraduate student nurses: The challenge of learning in resource poor clinical settings. International Journal of Africa Nursing Sciences, $1,35-42$.

27. Msiska, G., Munkhondya, T., \& Chilemba, E. (2014). Undergraduate students' perception of the role of the nurse educator during clinical placements in Malawi. Journal of Nursing, 4, 836 - 847.

28. Murphy, F., Jones, S., Edwards, M., James, J., \& Mayer, A. (2009). The impact of nurse education on the caring behaviours of nursing students. Nurse Education Today, 29(2), 254 - 264.

29. Neubauer, B. E., Witkop, C. T., \& Varpio, L. (2019). How phenomenology can help us learn from the experiences of others. Perspectives on medical education, 8(2), 90-97. https://doi.org/10.1007/s40037-019-0509-2 Noddings, N. (2005). The challenges of caring in school: An alternative approach to education (2nd ed.). New York: Teachers College Press.

30. Paterson, B., \& Crawford, M. (2004). Caring in nursing education: An analysis. Journal of Advanced Nursing, 19(1), 164 - 173.

31. Read, C.Y., Vessey, J.A.,Amar, A.F., Cullinan, D.M., 2013.The challenges of inclusivity in baccalaureate nursing programs. J. Nurs. Educ. 52, 185-190.

32. Reuther B. (2014) Intersubjectivity, Overview. In: Teo T. (eds). Encyclopedia of Critical Psychology. Springer, New York, NY. https://doi.org/10.1007/978-1-4614-5583-7_459

33. Salehian, M., Heidary, A., Aghebati, N., \& Moonaghi H, K. (2017). Faculty-student caring interaction in nursing education: an integrative review. J Caring Sci , 6(3):257-67. doi: 10.15171/jcs.2017.025.

34. Shosha, G. A. (2010). Employment of Colaizzi's strategy in descriptive phenomenology: A reflection of a researcher. European Scientific Journal, 8(27), 31 - 43.

35. Zamanzadeh, V., Shohani, M., \& Palmeh, T. (2015). Nursing students perception of instructors' caring behaviours at Tabriz University of Medical Sciences. Journal of Caring Sciences, 4(1), 55 - 62. DOI: $10.5681 /$ jcs.2015.006 